\section{Commentary: The pericardial autologous solution}

\author{
Antonio Miceli, MD, PhD
}

Infective aortic valve endocarditis with the involvement of mitro-aortic continuity and the anterior mitral valve leaflet is a severe and devastating disease associated with high mortality and morbidity. It occurs in $10.6 \%$ of cases of left-sided infective endocarditis, and early mortality ranges from $10 \%$ to $32 \% .^{1-3}$ Surgical operation is complex and requires radical debridement and reconstruction. Several surgical techniques have been proposed. ${ }^{4}$ Replacement of aortic and mitral valve with reconstruction of the mitroaortic continuity is the most common technique of choice, but the presence of 2 prosthetic valves may increase the risk of recurrent infection. Homografts and stentless xenografts represent excellent solutions, offering a low rate of recurrent infection and a low transvalvular gradient. ${ }^{5,6}$ However, they are technically more demanding, and future reoperation is a great challenge due to calcified structural degeneration. A monoblock aorto-mitral homograft has been also suggested as a surgical option for extensive bivalvular infective endocarditis.

In this issue of JTCVS Technique, Benedetto and colleagues ${ }^{8}$ propose a "biological" solution for the treatment of aortic and mitral endocarditis. Using autologous pericardium, the aortic valve is replaced according to the Ozaki procedure, and the mitral valve is repaired with a patch via a transaortic approach. This strategy is interesting and combines the benefits of a stentless valve without the use of prosthetic material. In addition, the transaortic approach avoids left atrial opening with consequently less surgical

From the Minimally Invasive Cardiac Surgery Department, Istituto Clinico Sant'Ambrogio, Milan, Italy.

Disclosures: The author reported no conflicts of interest.

The Journal policy requires editors and reviewers to disclose conflicts of interest and to decline handling or reviewing manuscripts for which they may have a conflict of interest. The editors and reviewers of this article have no conflicts of interest.

Received for publication May 19, 2020; revisions received May 19, 2020; accepted for publication May 28, 2020; available ahead of print June 15, 2020.

Address for reprints: Antonio Miceli, MD, PhD, Minimally Invasive Cardiac Surgery Department, Istituto Clinico Sant'Ambrogio, via L. G. Faravelli 16, Milano, Italy (E-mail: antoniomiceli79@alice.it).

JTCVS Techniques 2020;3:106-7

2666-2507

Copyright $(2020$ The Authors. Published by Elsevier Inc. on behalf of The American Association for Thoracic Surgery. This is an open access article under the CC BY-NCND license (http://creativecommons.org/licenses/by-nc-nd/4.0/).

https://doi.org/10.1016/j.xjtc.2020.05.029

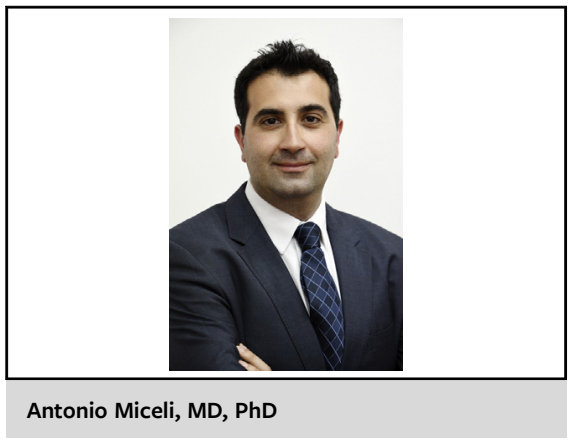

CENTRAL MESSAGE

Aortic valve neocuspidalization and transaortic mitral valve repair with autologous pericardium is a new technique for treating aortomitral endocarditis.

trauma and bleeding. The Ozaki procedure was developed mainly to treat degenerative aortic valve disease in patients with a small aortic annulus and patients who had rejected a mechanical valve. ${ }^{9}$ The indications were then expanded for aortic regurgitation and infective endocarditis. Midterm results have been excellent, with a $4.2 \%$ cumulative incidence of reoperation at 8 years reported. Nevertheless, 13 of 15 patients requiring reoperation $(87 \%)$ had infective endocarditis, with a rate of $0.3 \%$ per patient-year. The annual incidence rate for prosthetic valve endocarditis ranges between $0.12 \%$ and $0.35 \%$ per patient-year, raising some concerns regarding the benefit of aortic valve neocuspidalization in infective endocarditis. ${ }^{10,11}$ In addition, at 8-year follow-up, patients at risk for cumulative incidence of reoperation were only 54 out 850 , so a higher incidence of endocarditis might be expected. ${ }^{\text {? }}$

Finally, although autologous pericardium has good longterm durability in term of calcification, stiffness, and tears, most patients undergoing the Ozaki procedure will require a new operation at some point in their life. Reoperation is technically more demanding than primary operation, because of adhesions and the risk of iatrogenic injury to cardiac structures, especially in patients with less pericardium. Furthermore, the lack of prosthetic support might preclude the transcatheter aortic valve replacement (TAVR) approach. Several studies have shown that valve-in-valve TAVR is a safe and effective procedure with similar mortality as surgical AVR, at least in the short term. ${ }^{12}$ To date, no data have been reported on TAVR in a AVNeo (Ozaki) procedure. Regardless, my congratulations to Benedetto and colleagues for 
adding a new technique to the list of surgical treatments for aortomitral valve endocarditis: the pericardial autologous solution.

\section{References}

1. Forteza A, Centeno J, Ospina V, Lunar IG, Sanchez V, Perez E, et al. Outcomes in aortic and mitral valve replacement with intervalvular fibrous body reconstruction. Ann Thorac Surg. 2015;99:838-45.

2. Savage EB, Saha-Chaudhuri P, Asher CR, Brennan JM, Gammie JS. Outcomes and prosthesis choice for active aortic valve infective endocarditis: analysis of the Society of Thoracic Surgeons adult cardiac surgery database. Ann Thorac Surg. 2014;98:806-14

3. Tomšič A, Schneider AW, Palmen M, van Brakel TJ, Versteegh MIM, Klautz RJM. Extensive infective endocarditis of the aortic root and the aorticmitral continuity: a mitral valve sparing approach. Eur J Cardiothorac Surg. 2017;51:1100-17.

4. Ramlawi B, Reardon MJ. Endocarditis with involvement of the aorto-mitral curtain. Oper Tech Thorac Cardiovasc Surg. 2011;16:242-9.

5. Heinz A, Dumfarth J, Ruttmann-Ulmer E, Grimm M, Muller LC. Freestyle root replacement for complex destructive aortic valve endocarditis. J Thorac Cardiovasc Surg. 2014;147:1265-70
6. Miceli A, Croccia M, Simeoni S, Varone E, Murzi M, Farneti PA, et al. Root replacement with stentless freestyle bioprostheses for active endocarditis: a single-centre experience. Interact Cardiovasc Thorac Surg. 2013;16: 27-30.

7. Obadia JF, Henaine R, Bergerot C, Ginon I, Nataf P, Chavanis N, et al. Monobloc aorto-mitral homograft or mechanical valve replacement: a new surgical option for extensive bivalvular endocarditis. J Thorac Cardiovasc Surg. 2006;131: 243-5.

8. Benedetto U, Gergely S, Dimagli A, Sinha S. AVNeo (Ozaki) and transaortic mitral valve using autologous pericardium only for aortomitral endocarditis. J Thorac Cardiovasc Surg Tech. 2020;3:101-3.

9. Ozaki S, Kawase I, Yasashita H, Uchida S, Takatoh M, Kiyohara N. Midterm outcomes after aortic valve neocuspidalization with glutaraldehyde-treated autologous pericardium. J Thorac Cardiovasc Surg. 2018;155:22379-87.

10. Glower DD, Landolfo KP, Cheruvu S, Cen YY, Harrison JK, Bashore TM, et al Determinants of 15-year outcome with 1,119 standard Carpentier-Edwards porcine valves. Ann Thorac Surg. 1998;66(suppl):S44-8.

11. Ivert TS, Dismukes WE, Cobbs CG, Blackstone EH, Kirkilin JW, Bergdahl LA Prosthetic valve endocarditis. Circulation. 1984;69:223-32.

12. Nalluri N, Atti V, Minir AB, Karam B, Patel NJ, Kumar V, et al. Valve-in-valve transcatheter aortic valve implantation (ViV-TAVI) versus redo surgical aortic valve replacement (redo-SAVR): a systematic review and meta-analysis. $J$ Int Cardiol. 2018;31:661-71. 